4 of cases closed at Practice Committee (the most serious stage of the FtP process) where those with more time on the register were less likely to have been involved.

The issue of race matches findings of other healthcare regulators such as the General Medical Council (GMC), which has spoken of a persistent 'overrepresentation' of complaints against ethnic minority doctors in recent years though it is unclear if that is to do with their ethnicity or professional performance.

The latest GMC report ${ }^{4}$ looking at the state of medical education and practice found that black and minority ethnic GPs were $20 \%$ more likely to face a patient complaint over fitness to practise and $30 \%$ more likely to be investigated by the GMC.

The GDC has issued figures following a Freedom of Information (FoI) request to show the number of dentists from each country of qualification whose titness to practise was found to be 'impaired' (meaning either suspension, conditions, erasure or a reprimand) between 2013 and 2016.

Looking at all countries combined for 2016, there were 204 dentists whose fitness to practise was 'impaired' and of those, $40.7 \%$ had a non-UK qualification despite that fact that only $28 \%$ of the dental workforce has a qualification from outside the UK.

Heated debate over fitness to practise and regulation looks set to continue.

1. GDC. Annual Report and Accounts: 2017. (20 June 2018). Available at https://www.gdc-uk.org/about/what-we-do/ publications (accessed 10 September 2018).

2. General Dental Council. Shifting the balance: a better, fairer system of dental regulation (January 2018). Available at www.gdc-uk.org/shiftingthebalance (accessed 10 September 2018).

3. Zahra D, Roberts M, Bryce M, O’Brien T, Archer J. Analysis of fitness to practise case data for the General Dental Council (February 2017). Available at https:// www.gdc-uk.org/about/what-we-do/research (accessed 4 September 2018).

4. General Medical Council. The state of medical education and practice in the UK: 2017. 19 December 2017. Available at https://www.gmc-uk.org/-/media/about/ somep-2017-final-full.pdf?la=en\&hash $=3$ FC4B6C2B7EBD840017B908DBF0328CD840640A1 (accessed 4 September 2018).

\title{
Dentists invited to apply to join BDA policy body
}

Dentists are being invited to submit nominations to be elected to the BDA's Principal Executive Committee (PEC) the body that has overall responsibility for the control and direction of the policy and affairs of the BDA.

Members can self-nominate but need to have three other members to support their candidacy.

Nominations are being sought for the following seats on the PEC:

- UK-wide (one seat)

- Northern Ireland (one seat)

- England North (one seat)

- England South West (one seat)

- England Yorkshire and Humber (one seat).

There are 15 members on the PEC and each person will have a share of overall responsibilities.

Usually this requires attendance at all meetings of the PEC (around five a year); attendance at own country council meetings (usually three a year); attendance at UK Council meetings (around two a year); sitting on one to two sub committees/issue specific forums; and attendance at general meetings of the BDA.

It is anticipated that the approximate time commitment for a member of the PEC will be 20 days per year, with an annual remuneration of $£ 15,000$.

If successful, a person's position on the PEC will last until December 2021, with the opportunity to stand for a further full three-year term of office at that point.

Because membership of the PEC carries significant organisational and legal responsibilities, there is an induction programme for those elected and ongoing training provided.

Nomination forms must be submitted online by 5 pm on 26 October 2018. A link to the online nomination portal can be found at www.bda.org/elections

For more information, please contact the BDA's Election Manager Stephen Skelton by calling 02075634141 or emailing stephen.skelton@bda.org. 